Bestmann, M., Pennacchioni, G., and Grasemann, B., 2021, Deformation-induced Japan twinning in quartz during incipient mylonitization: Geology, v. 49, https://doi.org/10.1130/G49077.1

SUPPLEMENTAL MATERIAL

\title{
Deformation-induced Japan twinning in quartz during incipient mylonitization
}

Michel Bestmann, Giorgio Pennacchioni, and Bernhard Grasemann

\section{METHODS}

\subsection{Sample preparation}

Deformed quartz veins were cut normal to the general mylonitic shear foliation and parallel to stretching lineation (XZ-sections). The parallelism of the vein boundary with the mylonitic shear foliation defines the general shear zone boundary orientation and is used as the reference plane for the microstructural inventory including the orientation data of the electron backscatter diffraction (EBSD) data set (see below). The microstructure has been analyzed by optical polarized light microscopy. All optical images are presented with crossed polarizers, XPL. For scanning electron microscopy (SEM), especially EBSD investigations, the thin sections were finally chemo-mechanical polished with Silica Gel (SYTON) for 4-6 hours resulting in a damage-free high-quality surface. The thin section surface was coated with a $7 \mathrm{~nm}$ carbon layer in order to avoid charging during the long runs of high resolution EBSD analysis.

\subsection{EBSD analysis}

Several microstructural positions of the deformed quartz veins were analyse using a Thermo Fischer (former FEl) Helios nanoLab 600i field emission electron microscopy (incl. focused ion beam). The EBSD analyses were carried out with the new CMOS sensor technology of Oxford Instruments (Symmetry detector) in combination with AZtec 4.3 software. SEM working conditions were: acceleration voltage: $20 \mathrm{kV}$; beam current: $22 \mathrm{nA}$; working distance: 10-11 mm. Microstructural areas were scanned with a step size of 200-600 nm. The following camera/software condition were applied: EBSD camera distance: $176.5 \mathrm{~mm}$; number of detected bands: 12; band detection mode: TKD optimized; Hough number: 60; scanning mode: Speed 2 (156x128 pixel); background (number of frames): 400; background static/automatic: on; gain: 2 (high), frame average: 1; frame time: $1.3 \mathrm{~ms}$; match unit: quartz new (Oxford Instruments data base). These setting resulted in a scanning speed of 765 pattern per second and an average indexing rate between $96 \%$ and $99 \%$. Only holes in the 
sample surface and grain boundaries show non-indexed points. Careful post processing was carried out for removing most of the non-indexed points using the Oxford Instruments Software Channel 5 (Tango) following the method of Bestmann and Prior (2003).

Orientation data are plotted as pole figures (PF, equal area, lower hemisphere projection) where the horizontal axis marks the shear foliation (parallel to vein boundary / shear zone boundary) and is referred to as reference plane. Contouring was carried out with $15^{\circ}$ half-widths and $5^{\circ}$ cluster size. Contour maxima are given as multiple of random distribution (mrd). High orientation densities are colour coded in warm colours (yellow, red) and low densities in cold colours (blue, green). The maximum density is given. In the PFs the $a$-axes are plotted in upper and lower hemisphere which is useful for a fast discrimination of the occurrence of Dauphine twinning in combination with the orientation of the positive $\{r\}$ and negative $\{z\}$ rhomb planes. Misorientation axis for specific misorientation angle intervals are presented as inverse pole figures (IPF) with respect to the crystal reference system (equal area, upper hemisphere projection).

\section{TWINNING IN QUARTZ}

Quartz can show different types of twinning. In general twins are described as contact and/or penetration twins where the two parts are misoriented by an angle $\Theta$ about an axis normal to a plane $\{h k l i\}$ (Frondel, 1962). The two individuals are related to each other by a twin axis and/or a twin plane, which not necessarily has to be parallel to the compositional plane.

The most common twin in quartz are Dauphiné and Brazil twins (and their combination) where the $c$-axes of both twin domains are parallel to each other and therefore are classified as parallel axis twins (McLaren, 1986). Dauphiné twins are growth twins (Leydolt, 1855; Frondel, 1962) but also develop at the phase transition from $\beta$-quartz to $\alpha$-quartz (e.g. Van Landuyt et al., 1986; Piazolo et al., 2005). Dauphiné twins also can be induced by stress (Schubnikov and Zinserling, 1932) and play an important role in the initially process during deformation (e.g. Markaraaf, 1986; Lloyd, 2004; Menegon et al., 2011). Due to parallelism of the $c$-axes the Dauphiné twin domain cannot act as an orientation domain to accommodate preferentially higher shear strains (Tullis, 1970).

To a rarer extend quartz can be twinned by the inclined axis law (Frondel, 1962). Here mainly the Esterel twin and the Japan twin are common. The two twin individuals following the Esterel law are related by a twinning plane $r\{10-11\}$ or by a twin axis perpendicular to the twin plane. The compositional plane is parallel to the twin plane $r\{10-11\}$. The $c$-axes of the two individuals enclose an angle of $76.32^{\circ}$. The two individuals can be transferred into each other by a rotation of $76^{\circ}$ around one of the $\langle a\rangle$ axis (misorientation axis). In general, Esterel twinning is considered as growth twin 
during magmatic crystallization. However, Trepmann and Spray (2006) found evidence that Esterel twins also can be formed during granulite metamorphism.

The most common inclined axis twin law is Japan twinning (McLaren, 1986). $\alpha$ and $\beta$-quartz show the same twin elements / geometry (Frondel, 1962). Since the Schober quartz veins developed at 510-590 ${ }^{\circ} \mathrm{C}$ and 0.5-0.6 GPa (Linner, 1999) and were deformed at lower greenschist facies condition the rocks were consistently in the $\alpha$-quartz stability field. Japan-Law twinning is characterized by an angle of $84.55^{\circ}$ between the two $c$-axes. This is also the misorientation angle around an axis perpendicular to one of the prims planes $m\{10-10\}$. The two individual are related by a twin plane \{11-22\} and/or by a twin axis (near [11-23]) perpendicular to the twin plane (Frondel, 1962; Zhao et al., 2013). In dependence of the combination of left-handed and right-handed crystals, the twin element is either a twin plane or a twin axis. Consequently, there are four types of Japan twins and only for one the compositional plane is a twin (or mirror) plane and can be related as a symmetrical tilt boundary (e.g. Gault, 1949; MacLaren, 1986). However, the handness of quartz cannot be discriminated by EBSD, therefore only two types of Japan twin (Tpye I \& III and Type II \& IV, Zhao et al., 2013) can be distinguished by the pole figures, especially by the position of the positive rhomb planes $r\{10-11\}$.

Frondel (1962) also reported that both Japan twin individuals can be further twinned by the Dauphine twin law. This is the case for microstructure Site 1, especially for those new grains representing the Japan twin orientation (Fig. 1C). For Site 2 only the host grain shows intense deformation-induced Dauphiné twinning around the shear crack and at both sides of the tip (Fig. 2B). Fore Site 3 both, the clast and the new grains in the MSZ reveal Dauphiné twins (Fig. 3C).

\subsection{Japan-Law twin symmetry test}

For Japan twinning the two twin crystallographic orientations are mutually rotated of a theoretical angle of $84.55^{\circ}$ (angle between c-axes) about the normal to one of the prism planes (MacLaren, 1986; Sunagawa et al., 2004). Therefore, the two twin orientations are characterized in the PF by an overlap of one of the $m\{10-10\}$ poles and another overlap to one of the $\{11-22\}$ (twin plane) poles (Zhao et al., 2013).

In order to test if the Japan-Law twinning geometry did occur in the microstructure, the orientation data were rotated using the Channel5 software package Mambo. Following rotation operation were applied: 
(i) The c-axis maxima of the two orientation domains were rotated in a way that both maxima are aligned on the Z-axis of the PF.

(ii) The $c$-axis maxima were shifted along the Z-axis until the symmetry plane between the two maxima corresponds with the reference plane of the PF (X-axis) and therefore is parallel with the theoretical Japan-Law twin plane or theoretical compositional plane (one of the $\{11-22\}$ planes).

(iii) The orientation of host and the Japan twin domains were separately plotted and contoured. For the $\{m\}$ PF the maximum next to the periphery of the X-axis was marked (orange ellipse) and for the twin plane $\{11-22\}$ next to the Z-axis periphery (red ellipse), which corresponds to the Japan twin geometry of the rotated data set.

(iv) These marks were transferred to the common PFs where both the host domain and the Japan twin domain data are plotted. The overlapping area of both ellipses reveal the common data points of the host and the Japan twin domain.

(v) For the specific orientation geometry of the Japan-Law twin symmetry test the theoretical orientation of two Japan twin individuals (Type I \& III or Type II \& IV after Zhao et al., 2013) is marked for the $\langle c\rangle,\{m\},\{r\}$ and $\{11-22\}$ PFs as a reference orientation. Type I \& III and Type II \& IV can be discriminated by the position of the $r$ \{10-11\} poles. In the $\{11-22\}$ PFs the twin elements (twin plane, composition plane, twin axis) are given for Type I \& III and Type II \& IV (after Zhao et al., 2013). Note, not every Japan twin type contains all twin elements (Zhao et al., 2013).

\subsection{Japan-Law twin symmetry test with respect to the specific analyzed microstructures}

\subsubsection{Microstructure Site 1 (Fig. S2)}

The original data set already has an orientation geometry as it is defined for the Japan-Law twin symmetry test. No additional rotation of the data set was necessary. Note, additional to a strong peak at $60^{\circ}$ (related to Dauphiné twinning) the misorientation angle distribution shows a strong peak for boundaries around $90^{\circ}$ (Fig. S2B). The theoretical orientation of Japan-Law twin Type II \& IV (after Zhao et al., 2013) shows good conformity with the rotated data especially according to the misorientation angle between the $c$-axes $\left(\right.$ c. $86^{\circ}$ ), a common clustering around one of the $\{m\}$ poles (theoretical Japan-Law misorientation axis) and around \{11-22\} (theoretical Japan-Law twin plane), and additional an overlap next to the theoretical twin axis (marked in $\{11-22\}$ ). Note, for Japan-Law Type II \& IV the twin plane corresponds with the basement circle of the PF and therefore is the mirror or bisecting plane between the larger angle enclosed by the two $c$-axes $\left(96^{\circ}\right.$ instead of $\left.84^{\circ}\right)$. 


\subsubsection{Microstructure Site 2 (Fig. S3)}

The host grain shows intense Dauphiné twinning along the shear crack and around the tip where new grains are developed (Fig. S3A). Some of the new grains show a high angle and a symmetric orientation relationship to the surrounding host crystal (here presented by the Dauphiné twin domain) (Fig. S3C-D). The Japan-Law twin symmetry test (as described above) reveal good coherency with the Japan-Law twin geometry Type II \& IV (after Zhao et al., 2013) especially according to the misorientation angle (ca. $84^{\circ}$ ), a common clustering around $\{m\}$ (see also IPF in E) and $\{11-22\}$, and additional an overlap next to the theoretical twin axis (marked in \{11-22\}) (Fig. S3E). However, the misorientation angle distribution shows only a low frequency of data around $90^{\circ}$, which can be explained by the reduced number of new grains in this orientation relationship. Note, the other new grains have similar orientation as the surrounding host and can be attributed to subgrain rotation recrystallization (e.g. Bestmann and Prior, 2003) (Fig. 2C-II).

\subsubsection{Microstructure Site 3 (Fig. S4)}

The original data show an abrupt change in orientation between clast and microshear zone. However, the host at the margin to the microshear zone reveals a strong orientation dispersion (especially part A of the clast), so a clear misorientation angle relationship of $c$-axes between the original host orientation and the microshear zone is not given. Note, any further crystal plastic deformation will overprint and smear out a specific initial geometric crystallographic relationship between host and twin domain. This might explain why no pronounced secondary peak around $90^{\circ}$ is evident in the misorientation angle distribution diagram (Fig. S4C) and no specific clustering around $\{m\}$ exist (Fig. S4B). In order to test if an initial Japan twin or Esterel twin relationship is still evident we chose from the data set those parts which fulfill a misorientation angle of $85^{\circ}$ (Japan twin) or respectively $76^{\circ}$ (Esterel twin) between the $c$-axes of the clast (part B - less strained) and the new grains in the microshear zone. The tests indicate a good accordance for the host orientation with the theoretical orientation. But both twin individuals (Japan / Esterel) show a deviation from the theoretical orientation. Even when for the Esterel-Law the trace of the elongated new grain is in accordance with the orientation of one of the $r$-planes (compositional / twinning plane), there is no overlap in the $\{10-11\}$ PFs for the two individuals. The test shows that Japan-Law twinning is closer to the theoretical orientation as Esterel-Law twinning. Since the new grains have a more favorable easy slip orientation for prism< $a>$ slip ( $c$-axis oriented closer to the $Y$-axis of PF) than the host clast ( $c$-axis oriented close to the periphery of the PF), they will immediately start to localize strain and get stretched out. This strong crystal plastic overprint explains the deviation from an initial twin relationship, either caused by Japan-Law or Esterel-Law twinning. 


\subsubsection{Protolithic microstructure (Fig. S5A)}

In order to check if Japan twinning could be related to growth twinning during crystallization of the quartz vein, we analyzed a protolithic (less deformed) quartz vein sample by EBSD. We only found one example where the misorientation relationship between two grains enclose an angle of $84^{\circ}$ between the $c$-axes (Fig. S5A-I). However, the Japan-Law twin symmetry test reveals that the two grains did not have a common $m$-pole (theoretical Japan-Law misorientation axis) and therefore the Japan twinning law is not fulfilled. In the same sample we analysed a microstructure where the grain boundary between two grains show a specific lobate appearance, which is very similar to undulating twin boundaries of Japan growth twins presented by Lenart et al. (2012). The EBSD results reveal that the angle between the $c$-axes is $114^{\circ} / 66^{\circ}$ and the two crystals do not have a common $m$-pole (Fig. S5A-II) and therefore do not fulfil the Japan twin law.

\subsubsection{Low-strained protolithic microstructure (Fig. S5B)}

A low-strain sample shows elongated host grains with an interfingering microstructure, which theoretically could be a precursor of microstructure Site 1 and 3. The Japan-Law twinning test reveals that for both analysed microstructures $(I, I)$ the angle between the $c$-axes is $66^{\circ} / 63^{\circ}$ and therefore much smaller than the theoretical angle of ca. $85^{\circ}$. Even when the PFs show an overlapping area around $\{m\}$ the misorientation axis plots (IPF) does not confirm a clustering around $\{m\}$ for the misorientation angle range of $80-90^{\circ}$. Therefore, the Japan-Law twinning geometry is not fulfilled. 


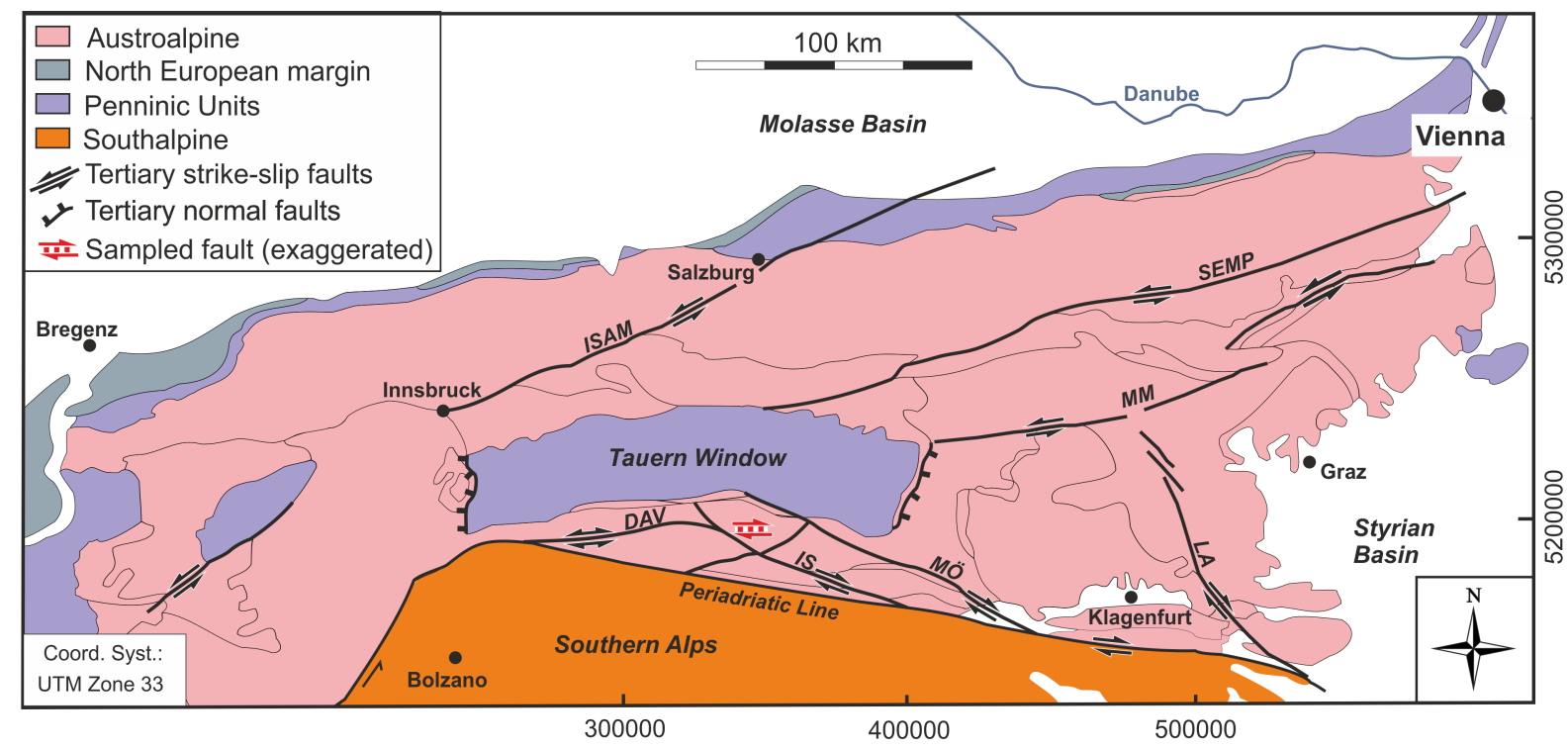

Figure S1. Simplified geological map of part of the Eastern Alps (modified after Schuster et al., 2014). Important tertiary fault systems are given. Note sampled fault (red stippled line) is a continuation in strike of the Defereggental-Anterselva-Valles fault (DAV). Innsbruck-Salzburg-Amstetten fault (ISAM); Salzach-Ennstal-Mariazell-Puchberger fault (SEMP); Mur-Mürztal fault (MM); Lavanttal fault (LA); Mölltal fault (MÖ); Iseltal fault (IS). Sample location coordinates: UTM33 326551 m E, 5198986 m N. 

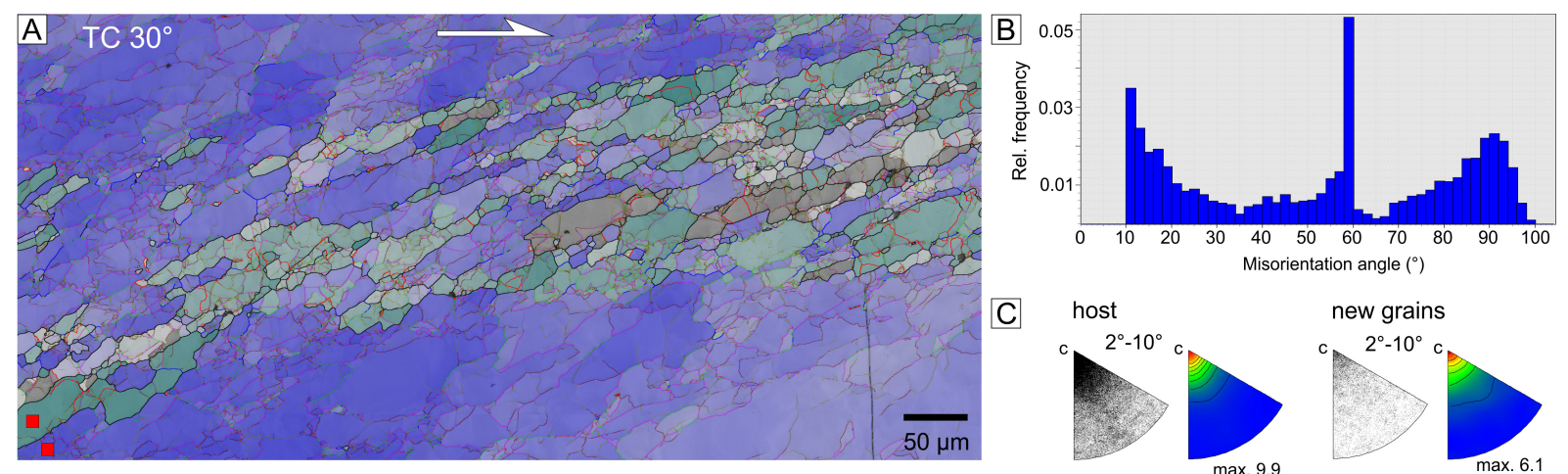

C
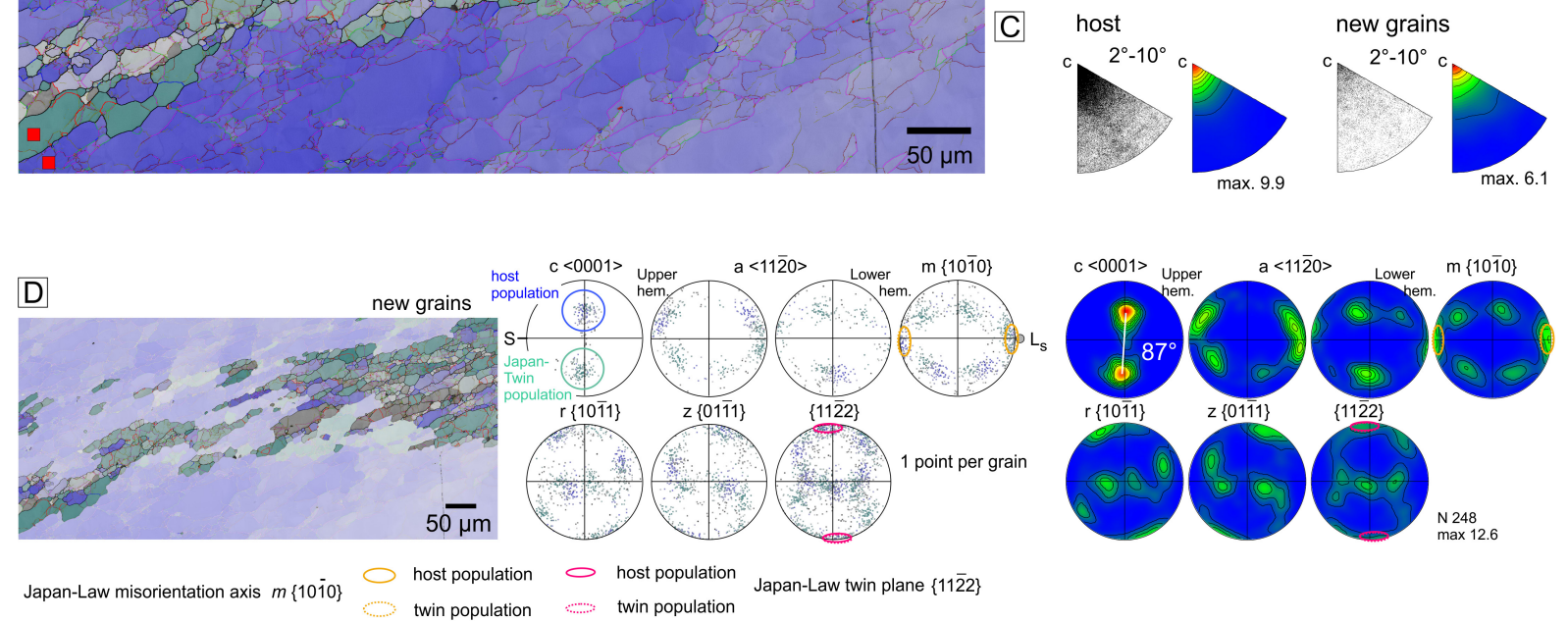
Japan-Law twin symmetry test
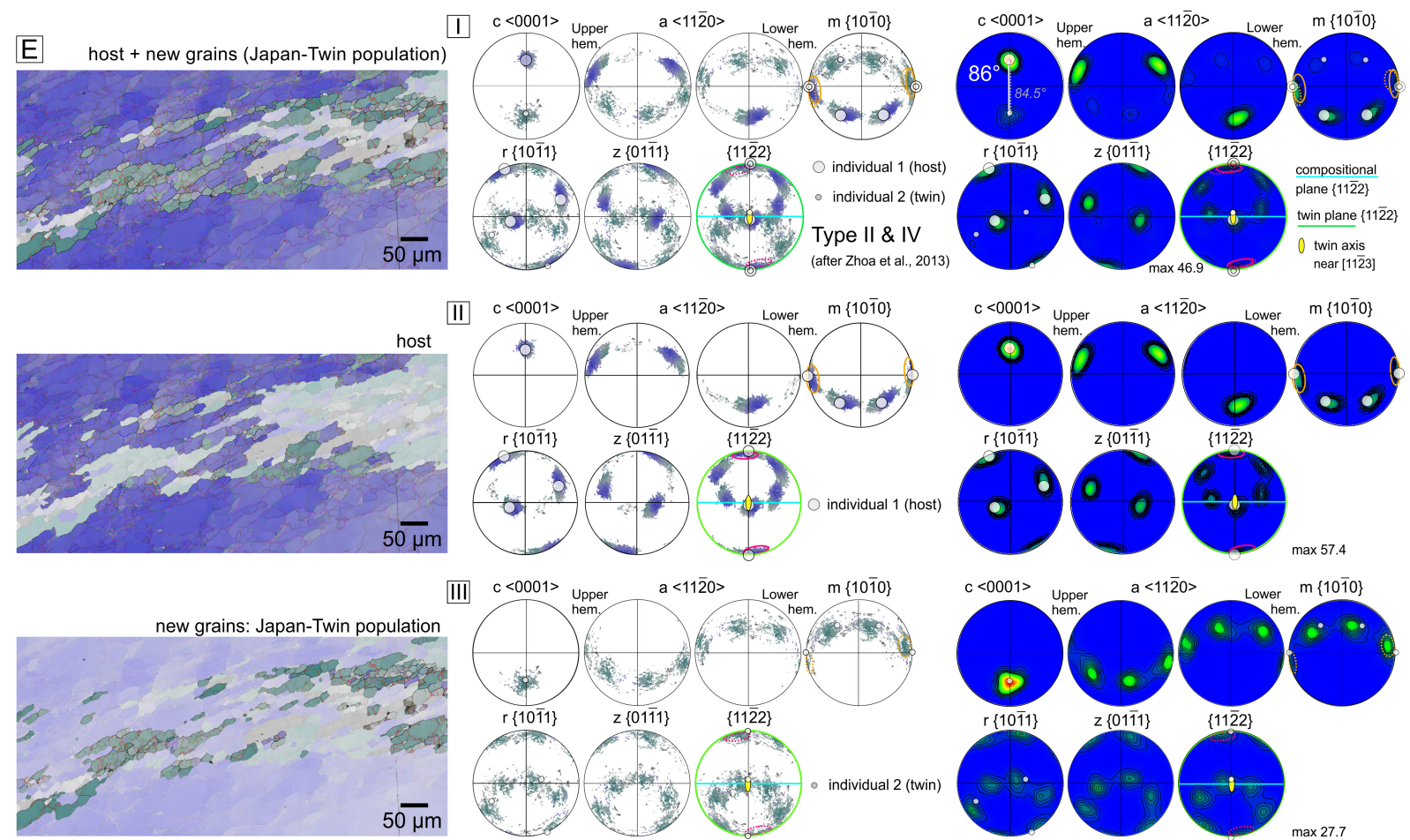

Figure S2. Detailed EBSD data analysis of microstructure Site 1 from Fig. 1. A: EBSD map (step size $200 \mathrm{~nm}$ ). The pixels of the host (blue) and new grains (teal) are colour shaded according to their angular misorientation from the points marked as red squares. Shading corresponds to $30^{\circ}$ orientation variation, the so-called texture component. Orientation map is superposed to the band contrast map (grey). Boundaries are colour coded with respect of misorientation angle intervals of

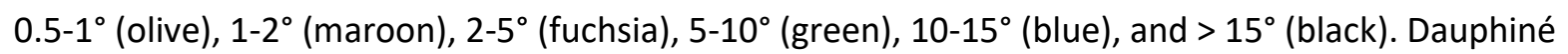
twin boundaries are in red $\left(60^{\circ}\right.$ rotation around $c$-axis with $5^{\circ}$ variation). B: Misorientation angle distribution. Note sharp peak at $60^{\circ}$ (Dauphiné twinning) and broad peak around $90^{\circ}$. C:

Misorientation axis of low angle boundaries (LAB) are plotted as inverse pole figures, IPF (equal area, upper hemisphere): host and new grains are presented separately. D-E: Orientation data are plotted 
as pole figures, $\mathrm{PF}$ (equal area, lower hemisphere). Contour maxima are expressed as multiple of random distribution ( $\mathrm{mrd}$; yellow and red marks highest mrd, blue and green lowest $\mathrm{mrd}$ ). Orange ellipses mark the correspondent maxima with respect to the overlap area to one of the $m\{10-10\}$ poles and the red ellipses to one of the $\{11-22\}$ Japan twin planes. Continuous ellipse lines are used to highlight the host orientation domain and dotted lines for the new grains (Japan twin population). The theoretical position of the compositional plane, the twin plane and the twin axis are colour coded and marked in the $\{11-22\}$ pole figure. Note, for the Japan-Law twin Type II \& IV (after Zhao et al., 2013) the twin plane (one of the $\{11-20\}$ plane) is perpendicular to the compositional plane and is represented as the basement circle of the PF, here marked in green. The twin axis is perpendicular to the twin plane and is near [11-23]. C: Orientation data of the new grains. PFs show one point per grain. Two populations of new grains can be identified: (i) new grains with a similar orientation as the host orientation (host population - blue) and (ii) new grains with a nearly $90^{\circ}$ orientation with respect to the host population (Japan twin population - teal). The angle between the $c$-axis maxima between the two populations is given in the contoured $c$-axis PF. Note, the host population of new grains can be referred to subgrain rotation recrystallization (e.g. Bestmann and Prior, 2003). D: Japan-Law twin symmetry test. Original data set already has an orientation as it is defined for the Japan-Law twin symmetry test (for more details see section 2.1 and 2.2.1 - above). I: Orientation data of host and new grains with Japan twin population. The theoretical orientation of two Japan twin individuals is marked in transparent grey tone for the $\langle c\rangle,\{m\}$ and $\{11-22\}$ PFs for an orientation where the compositional plane corresponds with the reference plane $S$ (X-axis of the PF). The theoretical angle of $84.5^{\circ}$ (grey font colour) between the $c$-axes of the two theoretical twin individuals is given and the angle between the two $c$-axis maxima of the data set (white font colour). II: Orientation data of the host grain. Note the dispersion path in the PFs points to lattice bending due to dislocation creep and subgrain rotation. Dauphiné twinning is rare in the host grain. III: Orientation data of new grains, which refer to the Japan twin population. Dauphiné twinning occurs frequently in the new grains. 

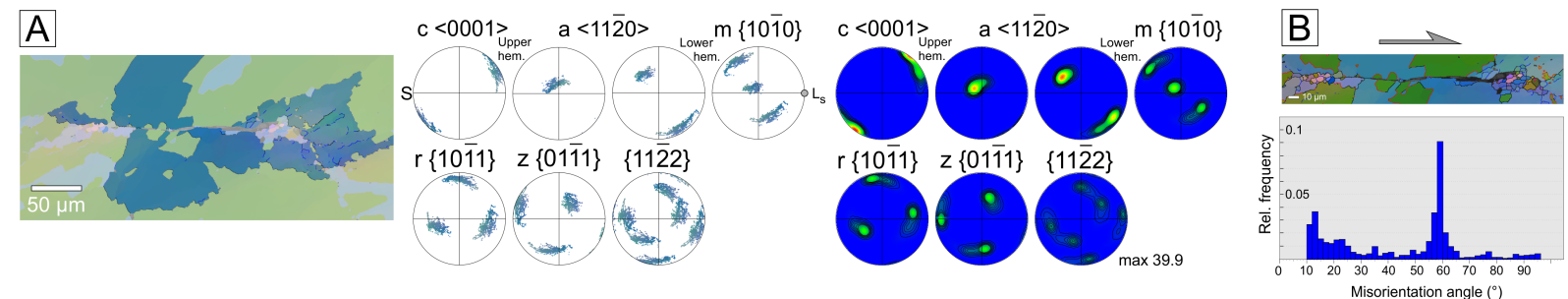

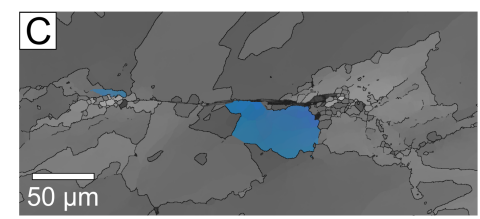

$c<0001>\quad a<11 \overline{2} 0>\quad m\{10 \overline{1} 0\}$

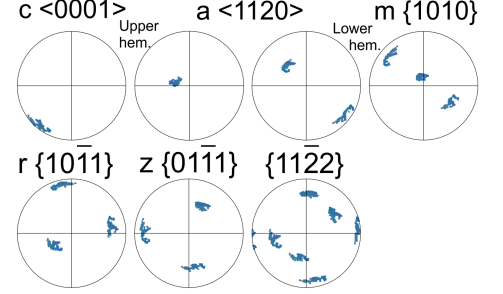

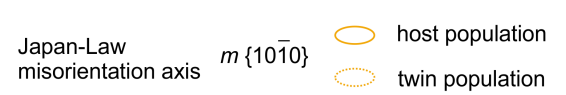
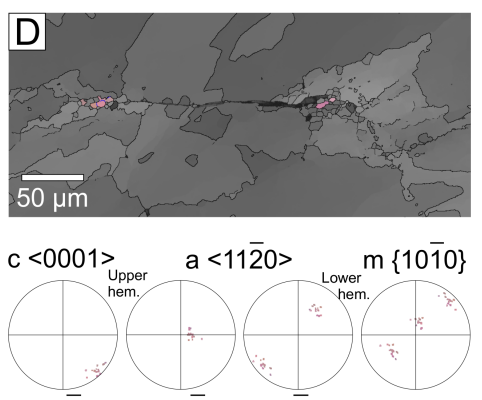

$r\{10 \overline{1} 1\} \quad z\{01 \overline{1} 1\} \quad\{11 \overline{2} 2\}$

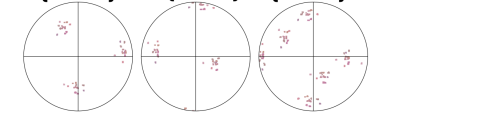

Japan-Law $_{\{11 \overline{2} 2\}} \bigcirc$ host population $\begin{array}{l}\text { Japan-Law } \\ \text { twin plane }\end{array}$ 111 22$\} \quad$ twin population
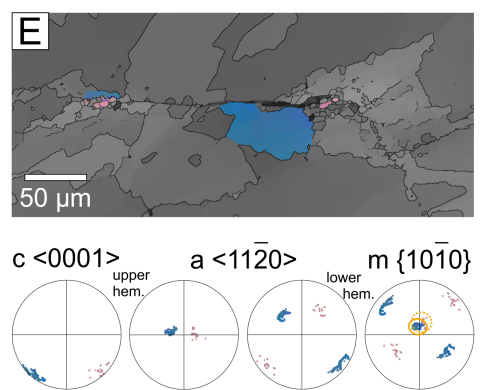

$r\{10 \overline{1} 1\} \quad z\{01 \overline{1} 1\} \quad\{11 \overline{2} 2\}$
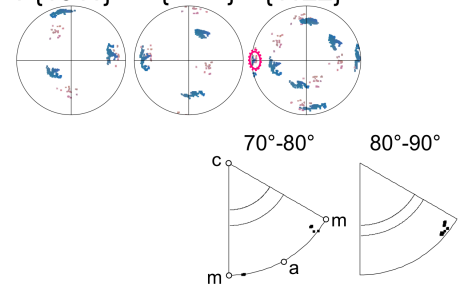

Japan-Law twin symmetrytest
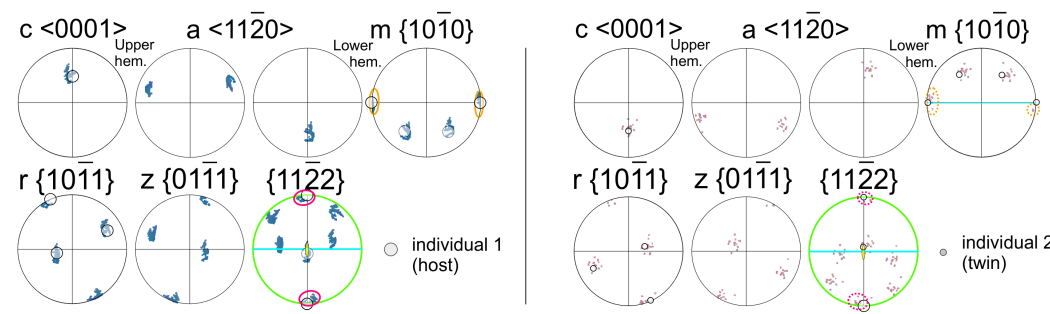

$r\{10 \overline{1} 1\} \quad z\{01 \overline{1} 1\} \quad\{11 \overline{2} 2\}$

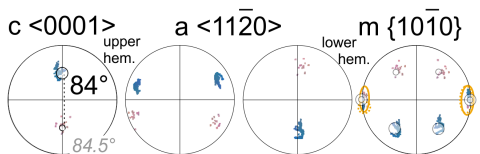

$r\{10 \overline{1} 1\} \quad z\{01 \overline{1} 1\} \quad\{11 \overline{2} 2\}$

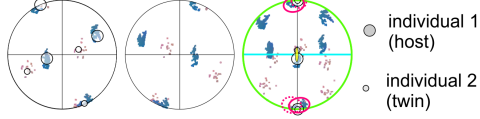
individuat
(twin)

twin plane $\{11 \overline{2} 2\} \quad$ compositional plane $\{11 \overline{2} 2\} \quad 0$ twin axis near $[11 \overline{2} 3]$

Type II \& IV (after Zhao et al., 2013)

Figure S3. Detailed EBSD data analysis of microstructure Site 2 from Fig. 2. A: Dauphiné orientation domain of host grain around the shear crack. B: Misorientation angle distribution along microshear zone. C-E: Original orientation data (upper PF raw) and orientation data related to Japan-Law twin symmetry test (lower PF raw). C: Orientation data of host (here represented by Dauphiné twin domain), next to shear crack. Note, the orientation corresponds to the maxima of the Dauphiné twin domain from the contoured PF as presented in A. Therefore, the orientation of $\mathrm{C}$ represents the initial orientation of the host, which probably was only to minor extent overprinted by crystal plastic deformation except of an initial deformation-induced transformation into Dauphiné twin orientation. D: New grains oriented with ca. $90^{\circ}$ to host orientation. E: Combined PF plot of C and D. Orange circle/ellipse marks overlapping clustering around one of the $\{m\}$ poles (Japan-Law twin misorientation axis) and red circle/ellipse around one of the \{11-22\} poles (Japan-Law twin plane). Further, there is an overlap of maxima next to the theoretical twin axis (marked in \{11-22\}). IPF plots of misorientation axis for misorientation angle of $70-90^{\circ}$ are given. Note, clustering next to $\{m\}$. The Japan-Law twin symmetry test was carried out as described in section 2.1. Figure description follows those of Fig. S2, but only $\mathrm{GB}>10^{\circ}$ and Dauphiné twin boundaries are plotted. 

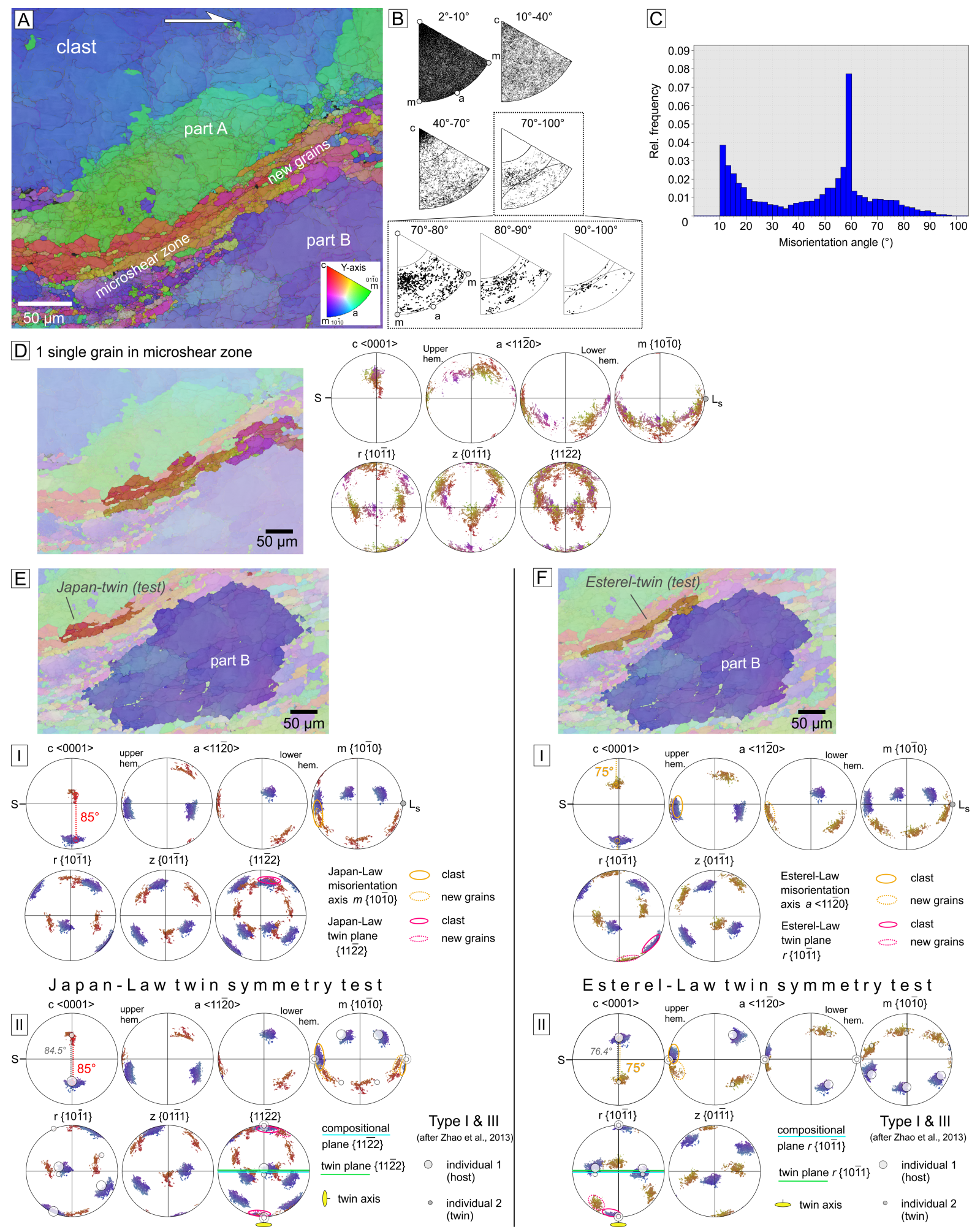

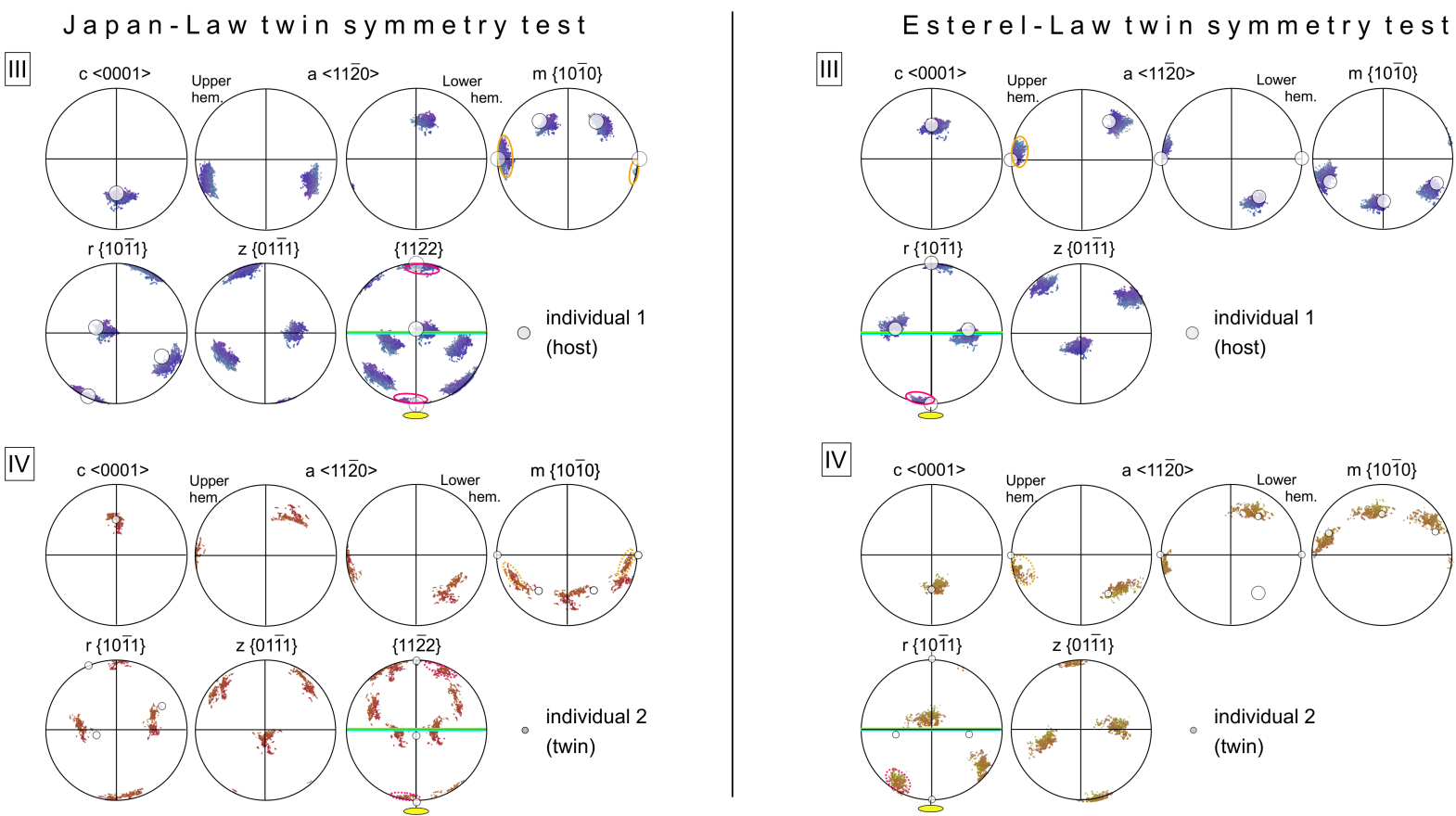

Figure S4. Detailed EBSD data analysis of microstructure Site 3 from Fig. 3. A: EBSD map (step size $200 \mathrm{~nm}$ ) colour coded with respect to the Y-axis of the PF - see insert. B: Distribution of misorientation axis for specific misorientation angle intervals. Note, for $70-100^{\circ}$ plot there is no specific clustering around $\{m\}$ and for $80-90^{\circ}$ only some data plot around $\{m\}$. C: Misorientation angle distribution. D: Orientation data of one single grain in microshear zone. Note, strong elongation (400 $\mu \mathrm{m})$ and aspect ratio $(7: 1)$ of the highly substructured grain. E: Area of the grain from D which enclose an angle of ca. $85^{\circ}$ between the $c$-axes with the clast (part B), related to a possible Japan-Law twin relationship. F: Area of the grain from $D$ which enclose an angle of ca. $75^{\circ}$ between the $c$-axes with the clast (part B), related to a possible Esterel-Law twin relationship. I: Original orientation data set. II: Rotated data set of I according to the geometry of the Japan-Law twin symmetry test (see section 2.1 - above) and Esterel-Twin symmetry test (following the same procedure as for Japan-Law twin symmetry test); see also section 2.2.3 - above. III: Orientation data of part B of the clast. IV: Orientation data of part of the new elongated grain from the microshear zone. Figure description follows those of Fig. S2. 


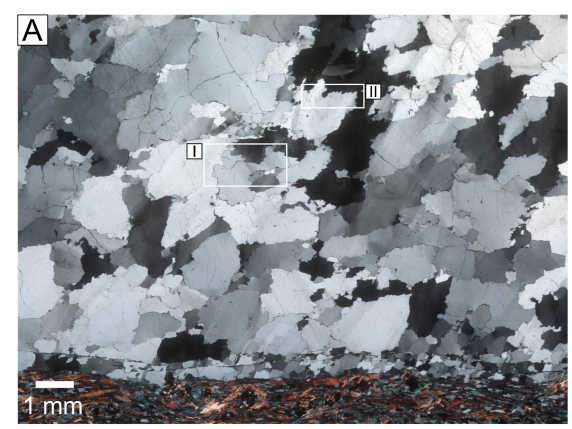

$m\{10 \overline{10}\} \begin{aligned} \text { individual } 1 & \text { individual } 2\end{aligned} \quad\{11 \overline{2} 2\} \quad$ individual 1

theoretical Japan-Law twin orientation relationship

- individual $1 \quad$ individual 2
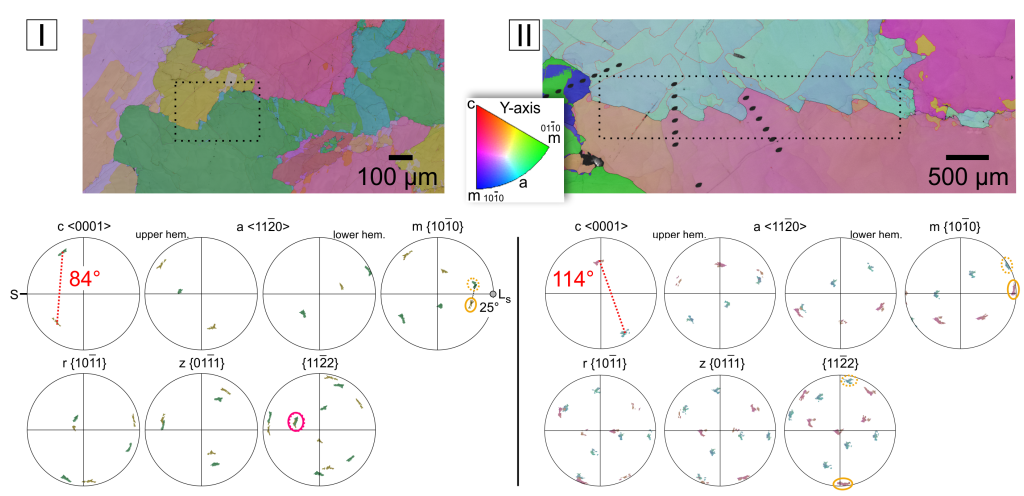

Japan-Law twin symmetry test
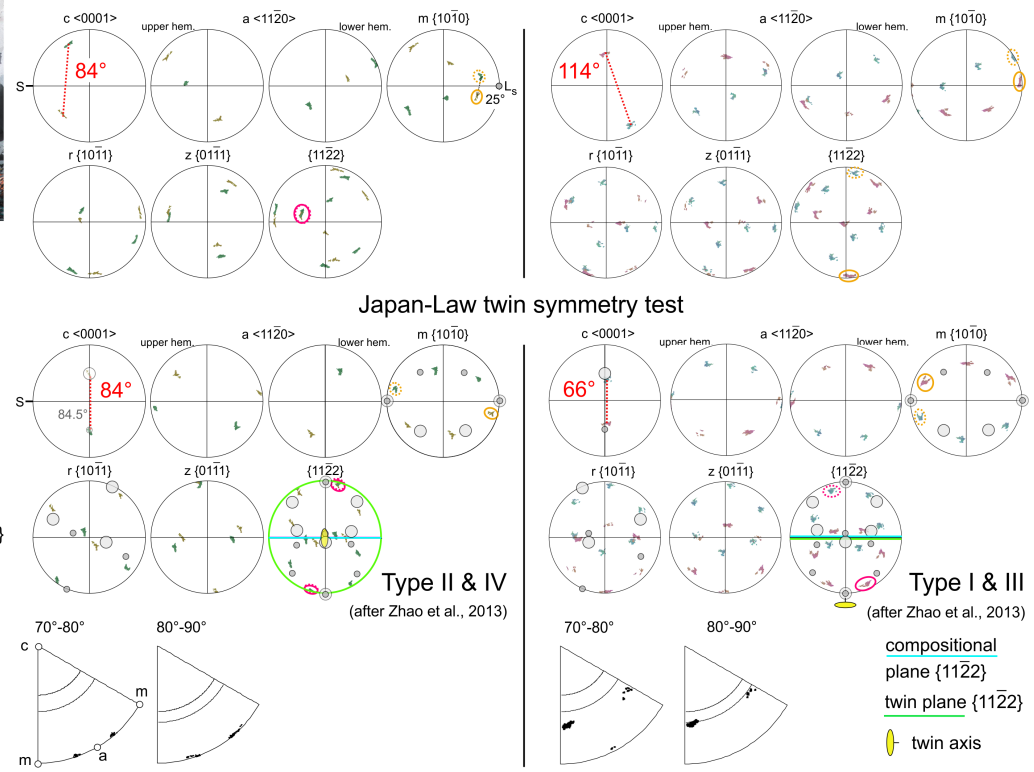

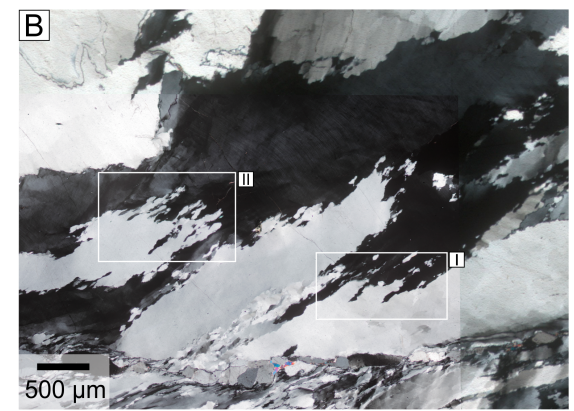

$m\{10 \overline{10}\} \quad$ individual $1 \quad\{11 \overline{2} 2\} \quad$ individual 1

theoretical Japan-Law twin orientation relationship

- individual $1 \quad$ individual 2

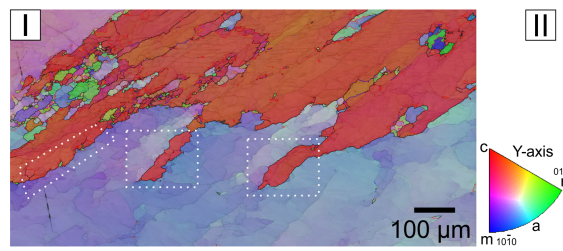

compositional twin plane $\{11 \overline{2} 2\}$ 0 twin axis
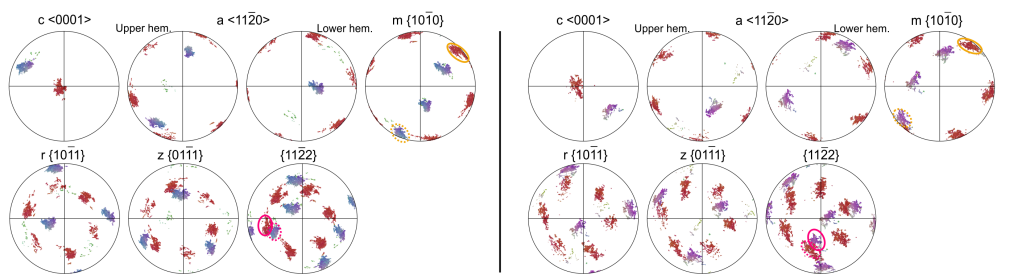

Japan-Law twin symmetry test
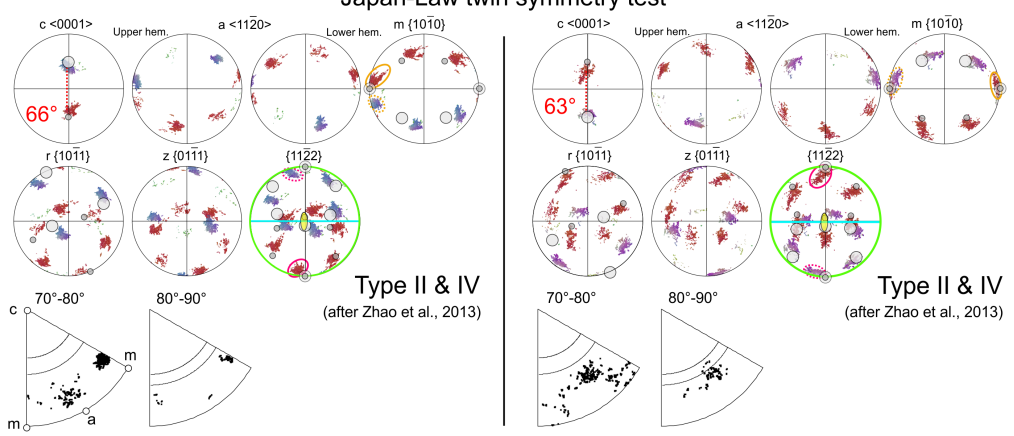

Figure S5. Microstructural analysis of protolithic quartz veins to check if Japan twinning can be related to growth twinning during crystallization of the quartz vein. A: Less deformed protolithic quartz vein. Optical micrograph (XPL) shows coarse-grained (grain size up to $5 \mathrm{~mm}$ ) microstructure. Lobate grain boundary microstructure indicates grain boundary migration. Together with the weak shape preferred orientation (SPO) the microstructure can be related to the previous high temperature deformation event before the mylonitic greenschist facies overprint took place (Thöni, 2006). (I): We only found one example where the misorientation relationship between two grains show an angle of $84^{\circ}$ between the $c$-axes. EBSD orientation map (step size $250 \mathrm{~nm}$ ) is colour coded 
with respect to the Euler angles; location is marked in A. Black (stippled) rectangle marks the area of two grains, which enclose an angle of $84^{\circ}$ between the $c$-axes. Upper PFs show original orientation data of area as marked in EBSD map. The weak dispersion path in PFs can be related to minor greenschist facies overprint (see also undulose extinction in A). Lower PFs show rotated orientation data after applying the Japan-Law twin symmetry test (see section 2.1 - above). IPFs show misorientation axis distribution for the relevant misorientation angles of the Japan-Law twinning. (II) Microstructure of lobate grain boundary as described for some twin boundaries of Japan growth twins (Lenart et al., 2012). EBSD map (step size $500 \mathrm{~nm}$ ) is colour coded with respect to the $\mathrm{Y}$-axis see insert. Black dotted lines are artefacts of former SIMS analysis spots. Stippled rectangle marks area presented as PF. Upper PFs show original orientation data revealing a misorientation angle of $114^{\circ}$ between the $c$-axis across the grain boundary. Lower PFs show orientation after applying JapanLaw twin symmetry test. Data are rotated in a way that the conjugate smaller $c$-axis angle $\left(66^{\circ}\right.$ visa $114^{\circ}$ ) enclose the horizontal line of the PF (representing the theoretical orientation of the Japan-Law twin / compositional plane). Note, there is no overlapping clustering around one of the $\{m\}$ poles see also section 2.2.4 - above. B: Optical micrograph (XPL) shows a strained protolithic microstructure with interfingering between elongated grains. EBSD maps (step size $600 \mathrm{~nm}$ ), as marked in optical microphotograph, is colour-coded with respect to Y-axis - see insert. Upper PFs show original orientation and lower PF after applying the Japan-Law twin symmetry test. Note, for both microstructures $(\mathrm{I}, \mathrm{II})$ the misorientation angle between the $c$-axes $\left(66^{\circ}, 63^{\circ}\right)$ is far off the theoretical Japan-Law twin angle $\left(84.5^{\circ}\right)$. Figure description follows those of Fig. S2.

Literature:

Bestmann, M., and Prior, D.J., 2003, Intragranular dynamic recrystallization in naturally deformed calcite marble: diffusion accommodated grain boundary sliding as a result of subgrain rotation recrystallization: Journal of Structural Geology, v. 25, p. 1597-1613.

Frondel, C., 1962, The System of Mineralogy, 7th Edition, Volume 3, Silica Minerals: John Wiley, New York, $334 p$.

Gault, H.R., 1949, The frequency of twin types in quartz crystals: American Mineralogist, v. 34, p. $142-162$.

Lenart, A., Samardzija, Z., Godec, M., Mitic, B., and Sturm, S., 2012, Twin-boundary formation in Japan-law twinned quartz crystals: European Journal of Mineralogy, v. 24, p. 509-517.

Leydolt, F., 1855, Ueber eine neue Methode, die Structur und Zusammensetzung der Krystalle zu untersuchen: Bericht der Akademie der Wissenschaften Wien, 15, p. 1-59.

Linner, M., 1999, Die P-T-t Entwicklung der Eklogite im Schoberkristallin als Beleg für frühalpidische kontinentale Subduktion im Ostalpinen Kristallin: Thesis, University of Vienna, 211 p.

Lloyd, G.E., 2004, Microstructural evolution in a mylonitic quartz simple shear zone: the significant roles of Dauphiné twinning and misorientation, in Alsop, G.I., Holdsworth, R.E., McCaffrey, K.J.W. and Hand, M. eds., Flow processes in faults and shear zones: Geological Society of London, Special Publication, v. 224, p. 39-61.

Markaraaff, J., 1986, Elastic behaviour of quartz during stress induced dauphiné twinning: Physics and Chemistry of Minerals, v. 13, p. 102-112. 
McLaren, A.C., 1986, Some speculations on the nature of high-angle grain boundaries in quartz rocks, in Hobbs, B.E. and Heard, H.C., eds., Mineral and Rock Deformation: Laboratory Studies, the Paterson Volume: American Geophysical Union, Washington DC, p. 233-247.

Piazolo, S., Prior, D.J., and Holness, M.D., 2005, The use of combined cathodoluminescence and EBSD analysis: a case study investigating grain boundary migration mechanisms in quartz: Journal of Microscopy, v. 217, p. 152-161.

Menegon, L., Piazolo, S., and Pennacchioni, G., 2011, The effect of Dauphiné twinning on plastic strain in quartz: Contribution of Mineralogy and Petrology, v. 161, p. 635-652.

Schubnikov, A., and Zinserling, K., 1932, Über die Schlag- und Druckfiguren und über die mechanischen Quarzzwillinge: Zeitschrift für Kristallographie, v. 83, p. 243-264.

Schuster, R., Daurer, A., Krenmayr, H.-G., Linner, M., Mandl, G. W., Pestal, G., and Reitner, J. M., 2014, Rocky Austria: The Geology of Austria - brief and colourful: Vienna, Geological Survey of Austria, 80 p.

Sunagawa, I., Imai, H., Takada, M., and Hoshino, Y., 2004, Morphogenesis of quartz crystals twinned after Japan Law: European Journal of Mineralogy, v. 16 (1), p. 91-97.

Thöni, M., 2006, Dating eclogite-facies metamorphism in the Eastern Alps - approaches, results, interpretations: a review: Mineralogy and Petrology, v. 88, no. 1-2, p. 10.1007/s00710-00006-00153-00715.

Trepmann, C.A., and Spray, J.G., 2006, Shock-induced crystal-plastic deformation and post-shock annealing of quartz: European Journal of Mineralogy, v. 18, p. 161-173.

Tullis, J., 1970, Quartz: preferred orientation in rocks produced by Dauphine' twinning: Science, v. 168, p. 1342-1344.

Van Landuyt, J., Van Tendeloo, G., and Amelinckx, S., 1986, Reply to "Intermediate phase between the $\alpha$ and $\beta$ phases of quartz": Physical Review B, v. 34 (3), p. 2004-2006.

Zhao, S-R., Xu, H-J., Wang, Q-Y., and Yang, K-G., 2013, Electron backscatter diffraction study of twins and intergrowths among quartz crystals in granite: Journal of Applied Crystallography, v. 46, p. 1414-1424, doi:10.1107/S0021889813017913. 